\title{
Use of Identical INN “Imiglucerase” for Different Drug Products: Impact Analysis of Adverse Events in a Proprietary Global Safety Database
}

\author{
So-Fai Tsang ${ }^{1} \cdot$ Shirali Pandya ${ }^{1} \cdot$ Kristina Barakov $^{1} \cdot$ Joan Keutzer $^{1} \cdot$ Grace Lewis $^{1} \cdot$ Leorah Ross $^{1} \cdot$ Selena Freisens $^{1} \mathbb{D}$
}

Accepted: 21 September 2021 / Published online: 12 January 2022

(c) The Author(s) 2022

\begin{abstract}
Introduction Approved in 1994 and assigned the International Nonproprietary Name (INN) imiglucerase by the World Health Organization, Cerezyme ${ }^{\circledR}$ (Sanofi Genzyme) is an enzyme replacement therapy used to treat Gaucher disease in $>90$ countries. At least two therapies approved outside the USA and the European Union, Abcertin ${ }^{\circledR}$ and Asbroder ${ }^{\circledR}$, have adopted the identical INN imiglucerase. Both drugs were approved via regulatory pathways not aligned with World Health Organization Similar Biotherapeutic Product guidelines.

Objective We analyzed whether the use of the identical INN "imiglucerase" for these drugs impacts adverse event (AE) reporting in the Sanofi Global Safety Database.

Methods First, we reviewed all imiglucerase individual case safety reports (referred to as cases) including AE data reported between January 2012 and March 2018 that contained Abcertin or Asbroder in the narrative. In a second analysis, we examined cases from Mexico reported between May 2013 and March 2018 to assess changes in imiglucerase reporting following the 2015 approval of Asbroder in Mexico.

Results Fifty-six cases mentioning Asbroder and none mentioning Abcertin were retrieved in the first analysis. Upon close review, the AEs of 45 cases (80.4\%) were attributed to Asbroder, one (1.8\%) to Cerezyme; the specific drug attribution for the AEs of ten cases (17.9\%) could not be determined. In the second analysis, a substantial increase in cases and AEs was observed in the period after Asbroder approval $(73$ cases with 150 AEs pre-approval vs 132 cases with 333 AEs postapproval). Twenty-three of 132 (17.4\%) post-approval cases reported discontinuation of treatment (19 related to Asbroder AEs, and four related to Cerezyme AEs). Infusion-associated reactions occurred in 25/132 cases (17 Asbroder related, six Cerezyme related, two indeterminate).

Conclusions This analysis demonstrates two potential consequences of identical INN use between Cerezyme and Asbroder: (1) an aggregate safety profile for Cerezyme that includes other products using the identical INN leading to inaccurate pharmacovigilance data and (2) healthcare providers switching, substituting, or potentially assuming interchangeability between the products. Identical INN use without the brand name differentiator may compromise pharmacovigilance data, potentially masking differences in safety profiles between products.
\end{abstract}

\section{Plain Language Summary}

The objective of this study was to assess the consequences of multiple drugs using the identical International Nonproprietary Name (INN) "imiglucerase" on adverse event reporting in the Sanofi Genzyme Global Safety Database. The World Health Organization established the INN system to identify drugs that are made of the same pharmaceutical substance and recommends that different products have distinct INN names. The INN imiglucerase was assigned in 1994 to Cerezyme ${ }^{\circledR}$ (Sanofi Genzyme), an orphan drug for the treatment of a rare disease known as Gaucher disease. In 2015, Asbroder ${ }^{\circledR}$ (ISU Abxis) was approved for Gaucher disease in Mexico and has adopted the INN imiglucerase. It was not approved as a biosimilar to Cerezyme. Most importantly, in a significant proportion of the adverse event cases reported, patients received a combination therapy of Asbroder and Cerezyme or Asbroder and "imiglucerase", suggesting that the shared INN may have led to

Selena Freisens

safreis@icloud.com

1 Sanofi Genzyme, Cambridge, MA, USA 
misconceived interchangeability of these products. Such confusion among healthcare providers poses a potentially serious risk to patient safety and health. These results are especially worrisome because they relate to products sharing an INN that were not approved as biosimilars. The findings from this study are also consistent with the view that Cerezyme and Asbroder may have different safety profiles. The implications of drug products having the same INN are discussed in the article as well as recommended solutions. To our knowledge, this is one of the first reports on real-world safety experience with biologics sharing the same INN name.

\section{Key Points}

The use of the same International Nonproprietary Name (INN) for different drug products may lead to inaccurate reporting of adverse events, resulting in masking of potential differences between products. This issue is of particular concern for products that have not undergone approval via biosimilar regulatory pathways that are aligned with World Health Organization Similar Biotherapeutic Product guidelines.

This analysis shows evidence of combined and intercalated use of different products sharing the same INN. The use of the identical INN may thus cause a misperception of the interchangeability of the drug products that were not approved as biosimilars.

Data from this study support the critical need for enforcing the World Health Organization INN naming guidelines to distinguish different drug products. It points to the necessity of creating an adequate and clear regulation and reporting system for safety events.

\section{Introduction}

Gaucher disease (GD) is a lysosomal storage disorder resulting from deficient activity of the lysosomal enzyme acid $\beta$-glucosidase (glucocerebrosidase) and the accumulation of its substrates, including glucosylceramide. Disease manifestations for Gaucher disease type 1 (GD1), the non-neuronopathic form of the disease, are multisystemic and progressive, and include splenomegaly, hepatomegaly, anemia, thrombocytopenia, and skeletal disease [1]. Early treatment has been shown to prevent irreversible damage, especially skeletal disease [2-5].

Thirty years ago, GD1 became the first disease to be successfully treated with enzyme replacement therapy. The first marketed enzyme replacement therapy and first treatment for GD1 was alglucerase (Ceredase; Sanofi Genzyme, Cambridge MA, USA), a placentally derived acid $\beta$-glucosidase approved in 1991; however, it was the development of recombinant, macrophage-targeted acid $\beta$-glucosidase (imiglucerase, Cerezyme ${ }^{\circledR}$; Sanofi Genzyme) in 1994 that allowed for the large-scale treatment of patients with GD [5]. The unique and consistent glycosylation pattern of Cerezyme results in targeted binding [6] and contributes to a structure-function relationship that yields the product's well-established safety and efficacy profile. Today, the use of Cerezyme in GD is supported by more than 25 years of real-world safety and efficacy data, demonstrating that it can prevent or reverse the hematologic, visceral, and bone manifestations of the disease, and that these benefits are sustained over long treatment periods [3, 5, 7-14].

The International Nonproprietary Name (INN) naming system was established by the World Health Organization (WHO) in the 1950s to provide health professionals with a unique and globally designated name to identify each pharmaceutical substance. According to the WHO Guidance on INN naming, the "existence of an international nomenclature for pharmaceutical substances, in the form of INN, is important for the clear identification, safe prescription and dispensing of medicines to patients, and for communication and exchange of information among health professionals and scientists worldwide" [15]. While it is standard practice to apply for an INN name through the WHO INN Programme, it is voluntary and not mandated internationally. The INN imiglucerase was assigned to Cerezyme by the WHO INN Programme in 1994.

In the last decade, at least two biologics for the treatment of GD1 have adopted the INN of imiglucerase. In 2012, a drug with the tradename Abcertin ${ }^{\circledR}$, manufactured by ISU Abxis, was conditionally approved in South Korea as longterm enzyme replacement therapy in patients with a confirmed diagnosis of GD1 [16]. Similarly, in 2015, a drug with the tradename Asbroder ${ }^{\circledR}$ (Laboratorios PiSA, S.A. de C.V.) was approved in Mexico [17]. The active substance for both Abcertin and Asbroder appear to be manufactured by ISU Abxis [18].

Although Abcertin and Asbroder both share the same INN imiglucerase with Cerezyme, both have been approved in their respective countries (South Korea and Mexico) via regulatory pathways that are not aligned with WHO Similar Biotherapeutic Product guidelines [19-23]. Abcertin was initially approved in South Korea through a national pathway that permitted the submission of phase 
III data after approval. This pathway is distinct from South Korea's pathway for approval of biosimilars and other orphan drugs [23]. Asbroder was approved in Mexico as an orphan drug, a regulatory pathway distinct from the biosimilar pathway [22,23]. As such, they should not be regarded as biosimilar and interchangeable with Cerezyme $[22,23]$.

Automatic substitution of a reference product with a product that has not been approved as a biosimilar raises potential concerns, including the risk of immunogenicityrelated safety issues, traceability, and diminished efficacy. Targeting of recombinant acid $\beta$-glucosidase to macrophages requires mannose receptor-mediated endocytosis via terminal mannose residues. The relative content of terminal mannose residue is a critical protein quality attribute that was optimized during the development of Cerezyme to enhance its uptake and effectiveness. The glycosylation profile of recombinant proteins may be impacted by aspects of the manufacturing process, some of which are designed to modify protein targeting, are proprietary to the company, and cannot be replicated. Differences in the manufacturing process between products, associated differences in glycosylation patterns, and repeated switches between products may increase immunogenicity and could possibly have negative effects on the safety and/or efficacy of those products [24]. $\mathrm{IgG}$ antibodies to imiglucerase developed in approximately $15 \%$ of patients treated with Cerezyme and did not appear to affect efficacy [25-27]. Almost all patients who develop antibodies to Cerezyme tolerize on their own or after following tolerization protocols [28, 29]. Immunogenicity data are not available for Abcertin or Asbroder and the prescribing information for both Abcertin and Asbroder restates the published data for Cerezyme and generalizes these data to "imiglucerase" [16, 17].

The shared use of the INN imiglucerase has the potential to cause confusion and misconceptions among regulators, healthcare providers (HCPs; including prescribers, pharmacists, and those who administer drugs), and patients regarding the interchangeability of Cerezyme and other products that use the same INN and have not been approved as biosimilars according to WHO biosimilarity guidelines [22, 30]. The use of the same INN imiglucerase may compromise the accuracy of adverse event (AE) data because the reporting of AEs using the INN imiglucerase could result in: (1) forced pooling of AEs for ISU Abxis-derived products and Cerezyme; (2) the opportunity to miss a potential safety signal from one of the drugs; and/or (3) inaccurate attribution of a potential safety signal to the wrong drug. This could result in inadvertent switching and substitution between Cerezyme and Abcertin or Asbroder based on formulary availability.

The objective of this analysis was to assess the impact of the use of the identical INN imiglucerase by Cerezyme and Abcertin/Asbroder on AE reporting in the Sanofi Global Safety Database (GSD). We report the results of two separate analyses of the GSD undertaken to assess whether AEs reported for imiglucerase were only for Cerezyme, or if in fact, there were AEs reported for any other drugs using the INN imiglucerase. The first analysis evaluated the cases in the GSD containing the tradenames Abcertin or Asbroder in the narrative. The second analysis assessed changes in reporting of AEs for imiglucerase following the 2015 approval of Asbroder in Mexico.

\section{Participants and Methods}

\subsection{Sanofi GSD}

The Sanofi GSD collects global AE data reported to the company from various sources, including Sanofi-sponsored clinical trials, literature reviews, and spontaneous reports from healthcare professionals, health authorities, or patients. Adverse event data are collected by INN and are reported regardless of causality. All AE reports are entered into a validated global pharmacovigilance database by trained and qualified personnel, in line with good pharmacovigilance practice and International Conference on Harmonisation criteria [31-34]. For the purposes of this analysis, the term AE more broadly also captured inappropriate drug usage. Individual case safety reports, referred to as 'cases', are documents that report on one or more AE.

All pharmacovigilance data are regularly reviewed and reported in a Periodic Benefit Risk Evaluation Report. The review is conducted to assess trends in the safety signal and the relative benefit-risk profile of Cerezyme.

\subsection{GSD Analysis}

All cases reported to the GSD for the INN imiglucerase between 1 January, 2012 and 1 March, 2018 were reviewed for mention of the tradenames Abcertin or Asbroder in the narrative. All cases were included whether reported by an HCP or a consumer, and regardless of the relationship.

\subsection{Pre-Asbroder vs Post-Asbroder Approval Analysis}

In the second analysis, cases reported to the database regarding patients in Mexico receiving imiglucerase were assessed before and after Asbroder approval. The reporting period chosen reflected a comparable period (approximately 872 days) before and after the Asbroder approval date of 11 October, 2015. The pre-approval period included reported AEs that occurred between 21 May, 2013 and 10 
October, 2015 (872 days prior to Asbroder approval); the post-approval period included reported AEs that occurred between 11 October, 2015 and 1 March, 2018 (872 days after Asbroder approval). It is assumed that because Cerezyme has been on the market for many years and was commercially available in Mexico since July 2011, the patient exposure to Cerezyme would be similar during both timeframes.

\subsection{Medical Review}

For all analyses, a single medical reviewer assessed the quality and nature of the available information included in the cases on use of Abcertin or Asbroder with or without Cerezyme, and attribution of AEs to one of these drugs. Adverse events were considered to represent an infusionassociated reaction (IAR) if they were product-related AEs occurring within 24 hours of the infusion. Upon medical review, each case was ascribed to one of three categories: (i) Asbroder or Abcertin alone, (ii) Cerezyme alone, or (iii) undetermined (either Asbroder/Abcertin or Cerezyme, or not enough information to determine), and then tabulated. Each case was tabulated only once.

\subsection{Data Analysis}

Descriptive statistics were calculated. No inferential statistical analyses were performed.

\section{Results}

\subsection{GSD Analysis of Imiglucerase AE Cases with Reported Tradenames Asbroder or Abcertin}

Fifty-six cases containing the tradename Asbroder in the narrative were retrieved from the Sanofi GSD between 1 January, 2012 and 1 March, 2018. No cases using the tradename Abcertin in the narrative were found. All 56 cases were reported from Mexico after the 11 October, 2015 approval of Asbroder and during the time of Asbroder market availability. Of the 56 cases, 16 were unsolicited and 40 were solicited (such as by a Patient Support Program). Most cases were assessed as non-serious ( 49 of $56,87.5 \%$ ).

Overall, 151 AEs were reported amongst the 56 cases. Of the 151 AEs, 44 AEs (29.1\%) were assessed as mild in severity, 19 AEs (12.6\%) were assessed as moderate, seven AEs $(4.6 \%)$ were assessed as severe, and severity was unspecified (not applicable, blank, or unknown) for 81 AEs (53.6\%).

In 18 of the 56 cases, the patients received a combination therapy of Asbroder and Cerezyme infusions or of Asbroder and "imiglucerase" infusions in various administration manners. Narrative reviews of these cases revealed reports of scenarios where the patients were prescribed a combination of Asbroder and Cerezyme, by mixing the two drugs in the same bag before infusion or infusing the two drugs via separate bags at the same infusion appointment, either intentionally or inadvertently, or "concomitantly" without further details, or administering according to an intentional intercalated schedule of alternating Asbroder with Cerezyme infusion every 2 weeks. Of the 18 cases receiving both drugs, after medical review, seven were ascribed to Asbroder infusion only. In one case, the patient was receiving combination therapy and the $\mathrm{AE}$ was ascribed to Cerezyme. Because of the confusing nature of the reports, the specific drug attribution for the AEs could not be determined in ten cases (17.9\%), despite a detailed review of the case reports. In total, after a detailed review, the AEs of 45 cases (80.4\%) were found to be attributable to Asbroder, one case (1.8\%) to Cerezyme; the specific drug attribution for the AEs of ten cases (17.9\%) could not be determined.

\subsection{Pre-Asbroder vs Post-Asbroder Approval Analysis on Imiglucerase with Reported Tradename Asbroder}

\subsubsection{AEs}

During the pre-Asbroder approval period (21 May, 2013 to 10 October, 2015), 73 cases with 150 AEs were reported. All cases and AEs were reported in patients taking Cerezyme, as expected (Fig. 1). Fifty cases were solicited and 23 were unsolicited. Twenty-seven cases were serious, and 46 cases were non-serious. The most frequently reported AEs during the pre-approval period were incorrect dosing (12.7\%), pneumonia (4.7\%), and an inappropriate schedule of drug administration (3.3\%) (Fig. 2a). Other AEs reported three or more times are presented in Fig. 2a. Of the 73 cases, there were no discontinuations of Cerezyme because of AEs. Medical review identified two IARs among the 73 cases (2.7\%), both related to Cerezyme and both non-serious.

During the post-Asbroder approval reporting period (11 October, 2015 to 1 March, 2018), 132 cases with 333 AEs were reported in patients while receiving imiglucerase therapy to the Sanofi GSD (Fig. 1). Of these, 116 cases were solicited, and 16 cases were unsolicited. Thirty-four cases were serious and 98 were non-serious.

As expected, based on the prior analysis, a medical review of the identified 132 cases with reported AEs among patients receiving imiglucerase during the period after the Asbroder approval in Mexico found that 56 of these cases (42.4\%) were attributable to Asbroder and the remaining 76 cases $(57.6 \%)$ were attributed to Cerezyme (Figs. 1,3$)$. The number of cases attributed to Cerezyme in the post-Asbroder 
Fig. 1 Comparison of adverse events (AEs) reported in patients receiving imiglucerase in Mexico before and after Asbroder approval. Infusionassociated reactions are product-related AEs occurring within $24 \mathrm{~h}$ of the infusion. IAR infusion-associated reactions

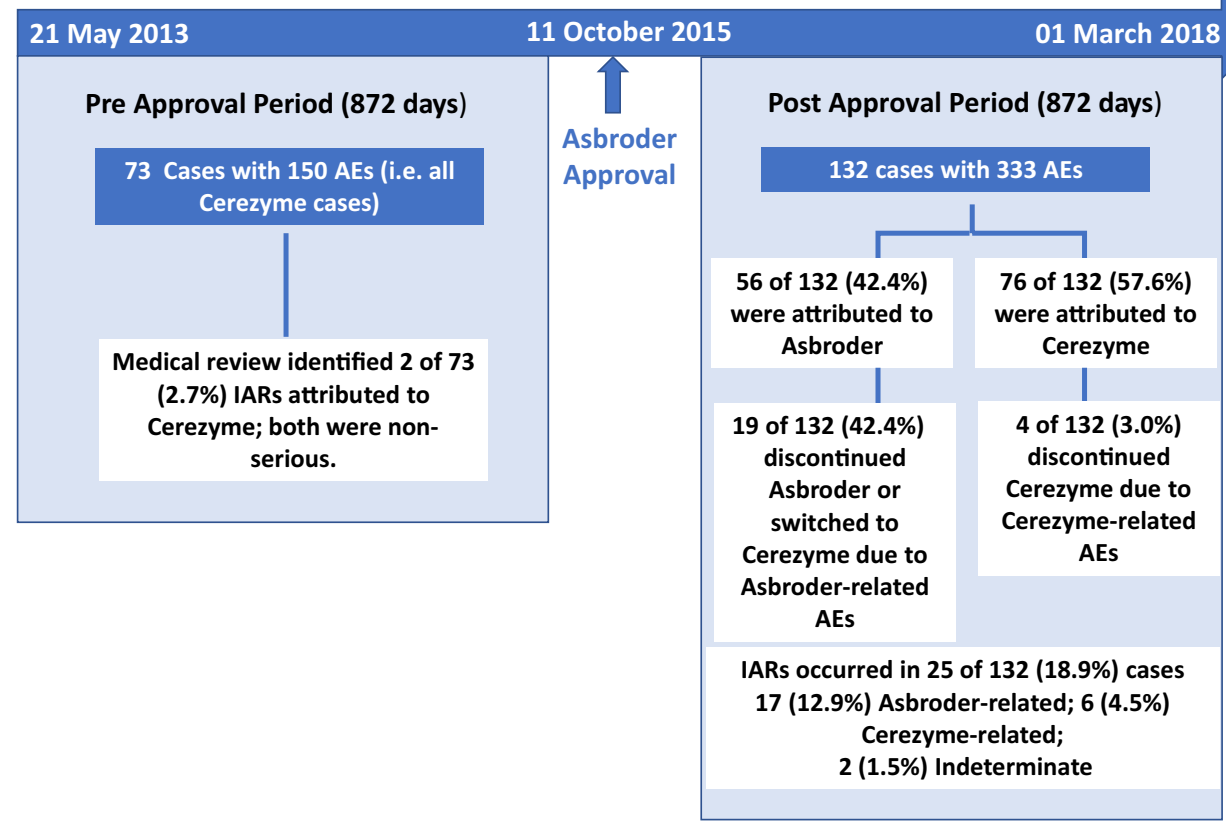

approval period ( $n=76$ ) is nearly equivalent to the number of cases attributed to Cerezyme in the same time exposure (872 days) prior to Asbroder approval $(n=73)$.

Of the 151 AEs reported among the 56 Asbroder cases in the post-approval period, the most frequent AEs reported were headache $(7.9 \%)$, nausea $(6.0 \%)$, and asthenia and dizziness (4.6\% each) (Fig. 2b). Of the 151 AEs, $4.6 \%$ were reports of off-label use. A total of ten cases with the AE preferred term of asthenia were reported after the approval of Asbroder in Mexico, in contrast to no cases of asthenia reported in the pre-Asbroder approval period. Asthenia was attributed to Asbroder in seven of the ten cases, and three cases were receiving Cerezyme therapy.

\subsubsection{Infusion-Associated Reactions}

Among the 132 cases in the post-Asbroder approval period, a total of 25 cases (18.9\%) of IARs were reported. Of the 25 cases of IARs, 17 (12.9\%) received Asbroder therapy, and six $(4.5 \%)$ received Cerezyme therapy; in two of the cases, the specific drug could not be ascertained because of the intercalated administration schedule or the lack of clarity on "imiglucerase" designation in the reports (Fig. 1). These percentages are conservative estimates, as the total number of cases was used as the denominator, regardless of which drug the IAR was attributed to. However, when calculated as a percentage of Asbroder or Cerezyme cases reporting an IAR in the post-Asbroder approval period, the upper limit of an IAR estimate could be as high as $30.4 \%$ (17/56) for Asbroder and $7.9 \%$ (6/76) for Cerezyme. Three cases of IARs were assessed as serious, two cases were attributed to Asbroder and one case was attributed to Cerezyme.

\subsection{Discontinuations Due to AEs}

Of the 132 cases reported for imiglucerase in the postAsbroder approval period, 19 cases (19/132 or $14.4 \%$ as a percentage of total imiglucerase cases, or $33.9 \%(19 / 56)$ as a percentage of "Asbroder" cases) discontinued Asbroder or switched to Cerezyme due to Asbroder-related AEs (Fig. 4). In most of these cases $(12 / 19,63.2 \%)$, the reported AEs that necessitated the discontinuation of the Asbroder infusion were IARs. In the same timeframe, 4 of 132 cases (4/132 or $3.0 \%$ as a percentage of total imiglucerase cases, or $5.3 \%(4 / 76)$ as a percentage of "Cerezyme" cases) discontinued Cerezyme due to Cerezyme-related AEs. Seventeen cases stopped Cerezyme treatment temporarily because of a concurrent affliction with plans to resume the Cerezyme infusion after recovery from the concurrent affliction.

\section{Discussion}

This analysis demonstrates that AEs attributed to Asbroder, a product using the INN imiglucerase, have been reported to the Sanofi GSD and mixed with the reported safety data for Cerezyme. There was a substantial increase in the number of reported cases and AEs with the INN of imiglucerase after the approval of Asbroder in Mexico. Nearly half of the 132 imiglucerase cases reported after Asbroder approval 


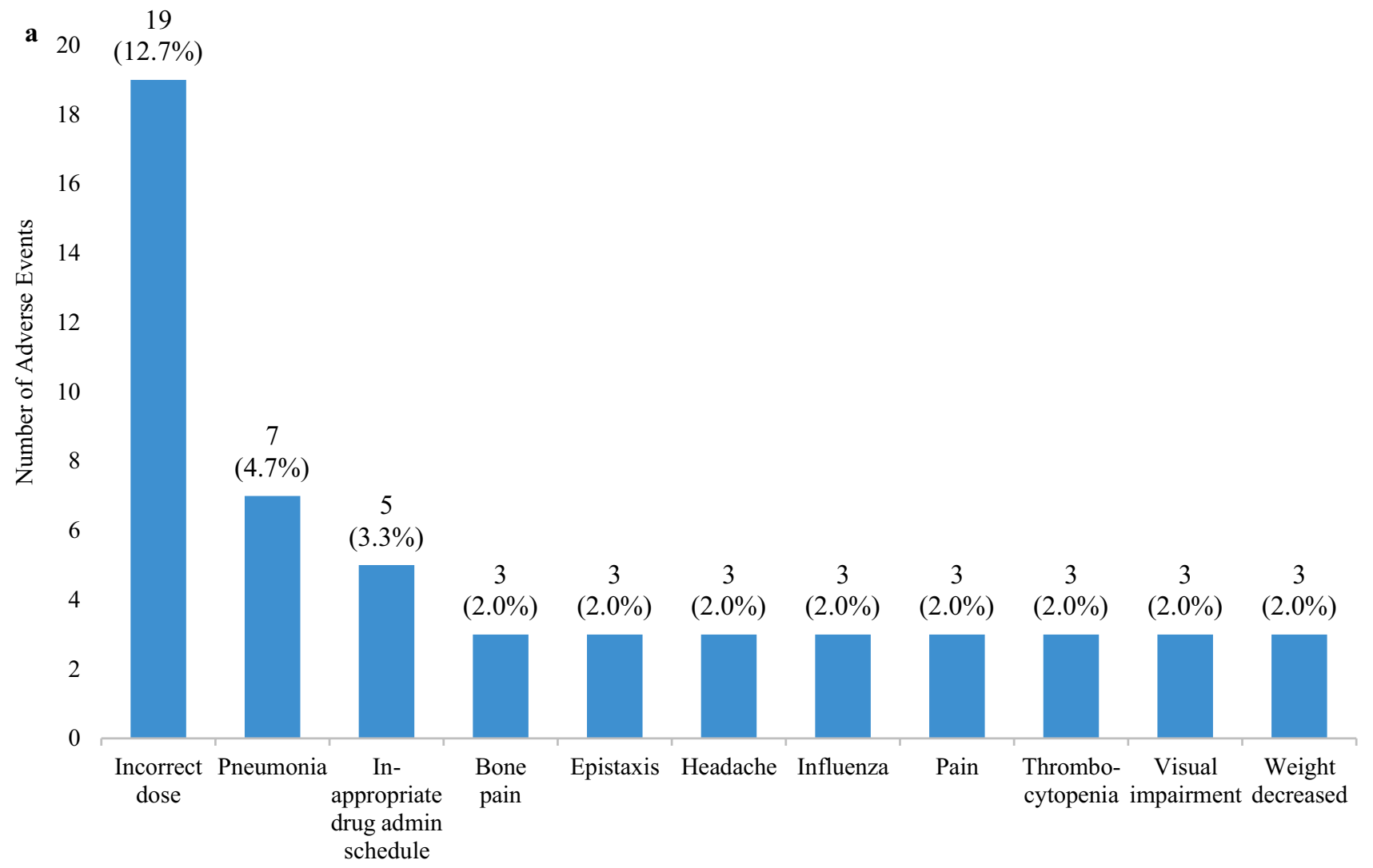

b 20

18

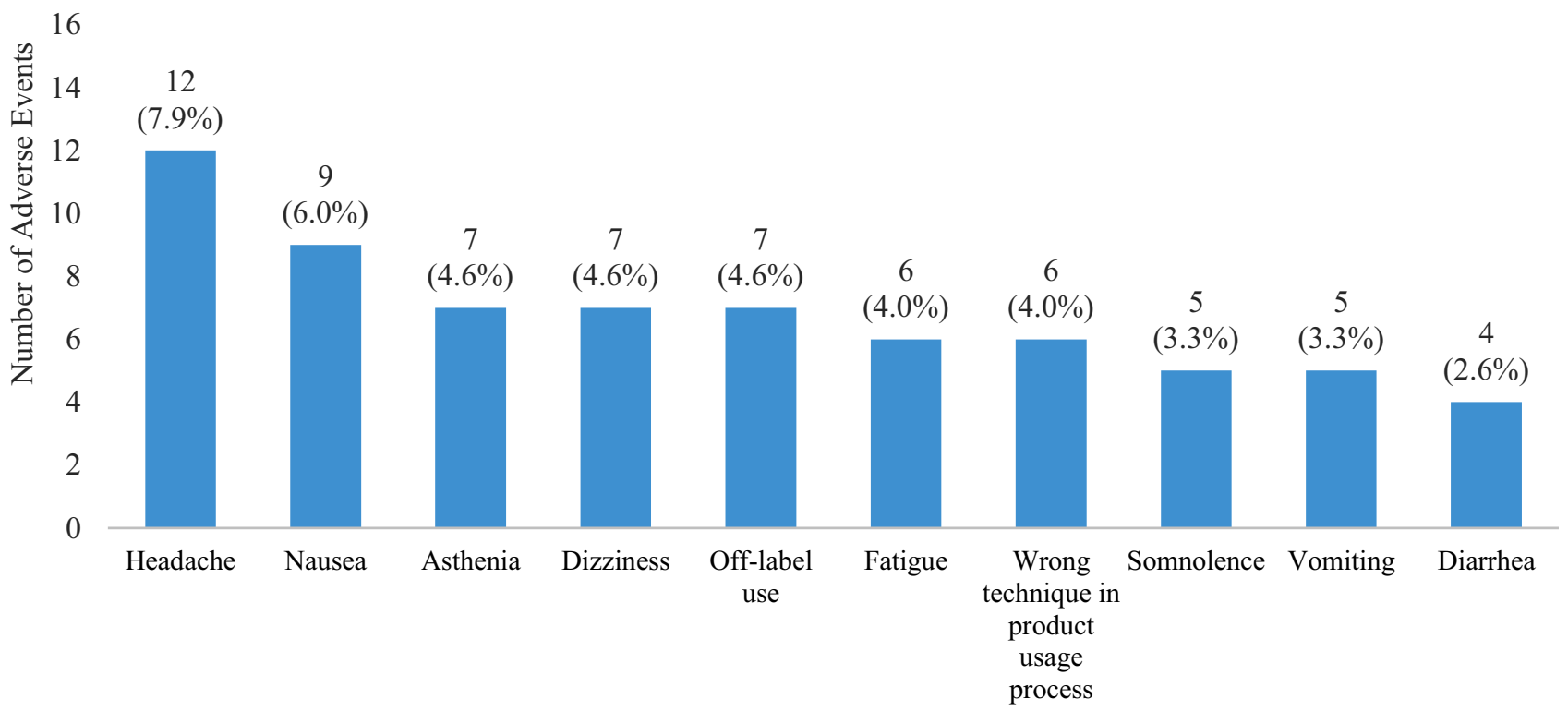

Fig. 2 a Most frequent (three or more) adverse events reported among Cerezyme cases. b Most frequent (three or more) adverse events reported among Asbroder cases 


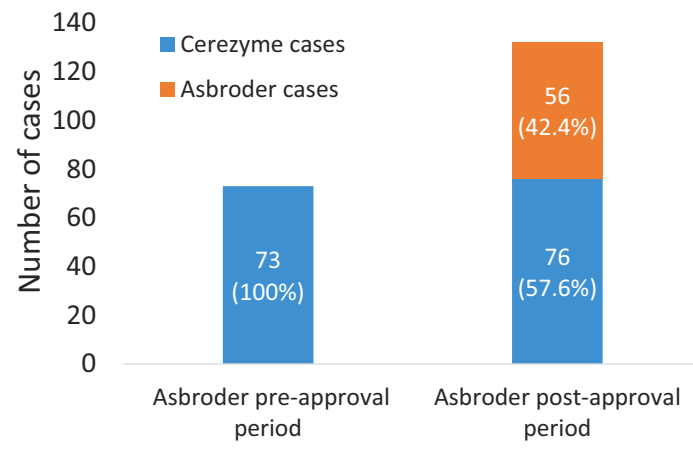

Fig. 3 Imiglucerase cases attributed to Cerezyme or Asbroder

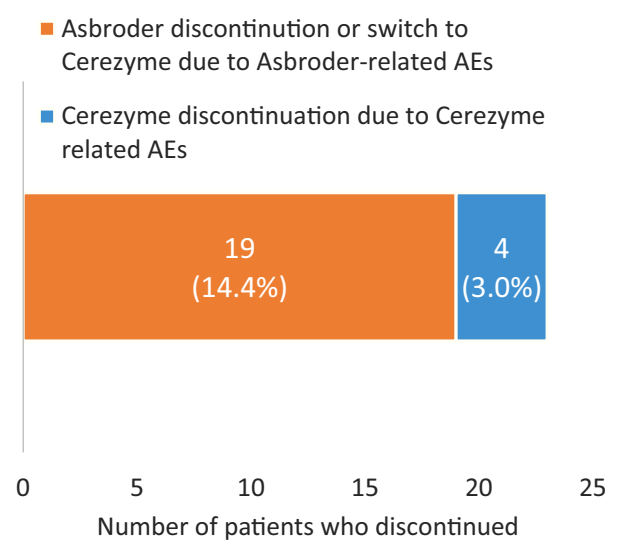

Fig. 4 Asbroder vs Cerezyme discontinuation rates after Asbroder approval $(N=132)$. $A E$ adverse event

were associated with Asbroder use but reported to the Sanofi GSD, the Cerezyme marketing authorization holder.

Historically, the rate of hypersensitivity reactions associated with Cerezyme, including the symptoms suggestive of an IAR, is approximately $3 \%$ according to the summary of product characteristics [25] and $6.6 \%$ according to the US package insert [26]. The Asbroder package insert also describes the rate of hypersensitivity for "imiglucerase" to be 6.6\% [17]. However, a review of the cases of Asbroder in Mexico in the safety database showed that, proportionally, there were approximately three-fold more IARs attributed to Asbroder infusion than to Cerezyme. Consequently, if this review of imiglucerase cases had not been performed, an inaccurate IAR rate of $18.9 \%$ would have been ascribed to Cerezyme in Mexico, which would be much higher than anticipated and could potentially lead to a false safety signal for Cerezyme. Safety data collected in the Sanofi GSD are periodically reviewed and submitted to regulatory authorities as an assessment report; inaccurate safety data reporting and interpretation in the GSD can thus lead to misinformed decision making and guidance by regulatory agencies.
This analysis also suggests potential differences between the reported safety profiles of Cerezyme and Asbroder, although this was not the primary purpose of the analysis. For example, the AEs most frequently attributed to Cerezyme were due to the drug's administration (incorrect dose) rather than an adverse effect caused by the drug. Further, the event of asthenia was only reported as an AE after Asbroder approval, and $70 \%$ of these cases were attributed to Asbroder. Substantially more cases discontinued Asbroder or switched from Asbroder to Cerezyme therapy due to reported AEs attributed to Asbroder compared with cases that discontinued Cerezyme therapy because of reported AEs attributed to Cerezyme. There are no published analytical, pre-clinical, or clinical data for Asbroder, nor are there any head-to-head or comparability studies with Cerezyme. As such, there is currently no rigorous publicly available data on the safety profile of Asbroder and how it compares to that of Cerezyme.

Asbroder presumably has a different manufacturing process from Cerezyme, which may result in a different safety profile. Nevertheless, the exact frequencies of AEs related to the use of each drug cannot be ascertained in this analysis because of the lack of precise information on the total patient exposure to the specific drugs in Mexico. Therefore, direct comparison of the frequency or severity of the AEs between Cerezyme and Asbroder is not feasible in this report, and the suggestion of trends toward differences in safety profiles is only qualitative.

Based on the analyses, in nearly a third of the 56 cases in which Asbroder was mentioned in the narrative, patients actually received a combination therapy of Asbroder and Cerezyme infusions or a combination of Asbroder and "imiglucerase" infusions in various administration manners. Combination therapy makes it impossible to differentiate the $\mathrm{AE}$ attribution to the correct drug. In this review, a sizable proportion $(10 / 56,17.9 \%)$ of imiglucerase cases in the database could not be attributed to a specific drug even upon a detailed analysis, owing to the confusing nature of the reports. Reasons for a lack of attribution included mixed/combination usage of both drugs in a single patient and uninterpretable distinction between drugs at the time of reporting or during the medical review process because of the shared use of the INN imiglucerase. This directly illustrates the concern of multiple products sharing an INN, particularly those that are not approved as a biosimilar.

The unconventional mode of intercalating or concomitant administration of Asbroder and Cerezyme in Mexico and the challenges in reporting AEs for products that use the same INN imiglucerase highlight the potential for confusion among HCPs and other reporters about the interchangeability of these products. This review also highlights the difficulty in ascertaining the causal relationship between AEs and a specific drug, as both Asbroder and Cerezyme are 
being prescribed, dispensed, and infused either simultaneously or sequentially at the same treatment or according to an intercalating schedule. The safety and efficacy of such administrations have not been evaluated.

The evidence of combination therapy with Asbroder and Cerezyme could possibly signal a misperception of interchangeability among HCPs potentially caused by the two marketed drugs having the same INN. It is not possible from these data to know precisely what a provider is thinking regarding the interchangeability of the products; however, the reports of AEs attributed to Asbroder to the Sanofi GSD, which is specifically for Cerezyme safety reporting, indicates that there may be some degree of confusion. In the interest of patient safety, it is important to be very clear as to which product the $\mathrm{AE}$ is attributed.

A limitation of our study is a focus on only one country (Mexico) where Asbroder is approved. In addition, the number of AEs studied here is relatively low. However, the primary purpose of the study was to determine whether Cerezyme and other imiglucerase products may be conflated in $\mathrm{AE}$ reporting rather than determining and comparing the safety profiles of the different products.

\section{Conclusions}

This analysis demonstrates that reporting AEs under the same INN imiglucerase could lead to (1) misreporting of AEs as being associated with potential safety signals or inaccurate pooling of $\mathrm{AE}$ data of products originated from ISU Abxis (such as Asbroder or Abcertin) with the Sanofi Genzyme product Cerezyme and (2) intercalated or concomitant treatment with both drugs, which could possibly be due to a misunderstanding of the interchangeability of the products with the same INN. The evidence from this analysis is consistent with the view that Asbroder may have a different safety profile from its reference product and should not necessarily be considered interchangeable with it. Most significantly, the findings highlight the challenges and confusion in $\mathrm{AE}$ reporting at both the $\mathrm{HCP}$ and marketing authorization holder level for products that use the INN imiglucerase (i.e., Cerezyme, Asbroder, and Abcertin). The use of the identical INN imiglucerase by three marketed and distinct products may potentially cause confusion for regulators, patients, and HCPs (including prescribers, pharmacists, and those administering the drug), with inadvertent switching, substitution, and potential misconceived interchangeability based on formulary availability. While the WHO INN naming guidance recommends that "for groups of glycoproteins/glycopeptides identified with a stem ... differences in glycosylation pattern are indicated by a Greek letter spelt in full and added as a second word to the name" [15], this convention is not strictly or consistently implemented by regulatory bodies worldwide. The continued labeling of products such as Asbroder and Abcertin with the same INN as Cerezyme compromises the accuracy of pharmacovigilance data, and ultimately, could impact patient safety. A prudent step to mitigate confusion and inaccurate safety reporting due to a common INN, as well as to protect patient health and safety, is the enforcement of WHO INN guidelines for requiring a different INN or INN identifier for different products, especially those that do not comply with international standards for biosimilarity.

To our knowledge, this is one of the first reports on realworld safety experience with biologics sharing the same INN name. As such, it points to the necessity of creating an adequate reporting system.

Acknowledgements The authors thank all of the patients with Gaucher disease and their physicians and healthcare personnel. The authors thank Cheryl Delacono for her contributions to this analysis and manuscript development and Shelton Panak (Strategic Regulatory and Scientific Communications; funded by Sanofi Genzyme) for her support in writing and editing the manuscript.

\section{Declarations}

Funding This project was funded by Sanofi Genzyme.

Conflict of interest At the time of submission, SP and SF were employees of Sanofi Genzyme. JK retired from Sanofi Genzyme, and KB, ST, GL, and LR are former employees of Sanofi Genzyme.

Ethics approval Pharmacovigilance data are collected as part of a routine safety follow-up for all approved products.

Consent to participate The data are anonymous and cannot be associated with any patients.

Consent for publication Not applicable.

Availability of data and material The data that support the findings of this study are available from Sanofi Genzyme, but restrictions apply to the availability of these data that are not publicly available. Data are, however, available upon reasonable request and with permission of Sanofi Genzyme.

Code availability Not applicable.

Authors' contributions ST, JK, LR, and SF developed the concept for the study. SP drafted the original manuscript. All authors were involved in the analysis and interpretation of the data, read the manuscript, provided critical revisions, approved the final manuscript, and have accountability for the accuracy and integrity of the content.

Open Access This article is licensed under a Creative Commons Attribution-NonCommercial 4.0 International License, which permits any non-commercial use, sharing, adaptation, distribution and reproduction in any medium or format, as long as you give appropriate credit to the original author(s) and the source, provide a link to the Creative Commons licence, and indicate if changes were made. The images or other third party material in this article are included in the article's Creative 
Commons licence, unless indicated otherwise in a credit line to the material. If material is not included in the article's Creative Commons licence and your intended use is not permitted by statutory regulation or exceeds the permitted use, you will need to obtain permission directly from the copyright holder. To view a copy of this licence, visit http://creativecommons.org/licenses/by-nc/4.0/.

\section{References}

1. Charrow J, Andersson HC, Kaplan P, Kolodny EH, Mistry P, Pastores G, et al. The Gaucher registry: demographics and disease characteristics of 1698 patients with Gaucher disease. Arch Intern Med. 2000;160(18):2835-43. https://doi.org/10.1001/archi nte.160.18.2835.

2. Mistry PK, Deegan P, Vellodi A, Cole JA, Yeh M, Weinreb NJ. Timing of initiation of enzyme replacement therapy after diagnosis of type 1 Gaucher disease: effect on incidence of avascular necrosis. Br J Haematol. 2009;147(4):561-70. https://doi.org/10. 1111/j.1365-2141.2009.07872.x.

3. Weinreb N, Barranger J, Packman S, Prakash-Cheng A, Rosenbloom B, Sims K, et al. Imiglucerase (Cerezyme) improves quality of life in patients with skeletal manifestations of Gaucher disease. Clin Genet. 2007;71(6):576-88. https://doi.org/10.1111/j.13990004.2007.00811.x.

4. Weinreb NJ, Charrow J, Andersson HC, Kaplan P, Kolodny EH, Mistry P, et al. Effectiveness of enzyme replacement therapy in 1028 patients with type 1 Gaucher disease after 2 to 5 years of treatment: a report from the Gaucher Registry. Am J Med. 2002;113(2):112-9. https://doi.org/10.1016/s0002-9343(02) 01150-6.

5. Weinreb NJ, Goldblatt J, Villalobos J, Charrow J, Cole JA, Kerstenetzky M, et al. Long-term clinical outcomes in type $1 \mathrm{Gau}-$ cher disease following 10 years of imiglucerase treatment. J Inherit Metab Dis. 2013;36(3):543-53. https://doi.org/10.1007/ s10545-012-9528-4.

6. Brady RO. Enzyme replacement therapy: conception, chaos and culmination. Philos Trans R Soc Lond B Biol Sci. 2003;358(1433):915-9. https://doi.org/10.1098/rstb.2003.1269.

7. Andersson H, Kaplan P, Kacena K, Yee J. Eight-year clinical outcomes of long-term enzyme replacement therapy for 884 children with Gaucher disease type 1. Pediatrics. 2008;122(6):1182-90. https://doi.org/10.1542/peds.2007-2144.

8. Andersson HC, Charrow J, Kaplan P, Mistry P, Pastores GM, Prakash-Cheng A, et al. Individualization of long-term enzyme replacement therapy for Gaucher disease. Genet Med. 2005;7(2):105-10. https://doi.org/10.1097/01.gim.0000153660. $88672.3 \mathrm{c}$

9. Barton NW, Brady RO, Dambrosia JM, Di Bisceglie AM, Doppelt SH, Hill SC, et al. Replacement therapy for inherited enzyme deficiency: macrophage-targeted glucocerebrosidase for Gaucher's disease. N Engl J Med. 1991;324(21):1464-70. https://doi.org/10. 1056/nejm199105233242104.

10. Charrow J, Dulisse B, Grabowski GA, Weinreb NJ. The effect of enzyme replacement therapy on bone crisis and bone pain in patients with type 1 Gaucher disease. Clin Genet. 2007;71(3):20511. https://doi.org/10.1111/j.1399-0004.2007.00769.x.

11. Grabowski GA, Leslie N, Wenstrup R. Enzyme therapy for Gaucher disease: the first 5 years. Blood Rev. 1998;12(2):115-33. https://doi.org/10.1016/s0268-960x(98)90023-6.

12. Sims KB, Pastores GM, Weinreb NJ, Barranger J, Rosenbloom $\mathrm{BE}$, Packman $\mathrm{S}$, et al. Improvement of bone disease by imiglucerase (Cerezyme) therapy in patients with skeletal manifestations of type 1 Gaucher disease: results of a 48-month longitudinal cohort study. Clin Genet. 2008;73(5):430-40. https://doi.org/10. 1111/j.1399-0004.2008.00978.x.

13. Weinreb NJ, Finegold DN, Feingold E, Zeng Z, Rosenbloom BE, Shankar SP, et al. Evaluation of disease burden and response to treatment in adults with type 1 Gaucher disease using a validated disease severity scoring system (DS3). Orphanet J Rare Dis. 2015;10:64. https://doi.org/10.1186/s13023-015-0280-3.

14. Wenstrup RJ, Bailey L, Grabowski GA, Moskovitz J, Oestreich $\mathrm{AE}, \mathrm{Wu} \mathrm{W}$, et al. Gaucher disease: alendronate disodium improves bone mineral density in adults receiving enzyme therapy. Blood. 2004;104(5):1253-7. https://doi.org/10.1182/ blood-2003-11-3854.

15. World Health Organization. Guidance on the use of international nonproprietary names (INNs) for pharmaceutical substances. Geneva: World Health Organization; 2017. https://www.who.int/ medicines/services/inn/FINAL_WHO_PHARM_S_NOM_1570_ web.pdf?ua=1. Accessed 28 Sept 2021 .

16. Abcertin [package insert]. ISU Abxis. Seoul; 2014.

17. Asbroder [product information sheet]. Laboratorios PiSA, S.A. de C.V. Guadalajara, Jai; 2014.

18. Comisión Federal para la Protección contra Riesgos Sanitarios (Cofepris), Marketing Authorization, Asbroder, at 2 (Nov. 10, 2015) (identifying ISU Abxis as the manufacturer of Asbroder's active substance, and Laboratorios PiSA S.A. de C.V. as the marketing authorization holder). https://www.gob.mx/cms/uploa ds/attachment/file/196773/Huerfanos_Otorgados_2015.pdf. Accessed 28 Sept 2021.

19. European Medicines Agency. Guideline on similar biological medicinal products. 23 October 2014. Committee for medicinal products for human use (CHMP). CHMP/437/04 Rev 1. https:// www.ema.europa.eu/documents/scientific-guideline/guidelinesimilar-biological-medicinal-products-rev1_en.pdf. Accessed 28 Sept 2021.

20. US Food and Drug Administration. Scientific considerations in demonstrating biosimilarity to a reference product guidance for industry. 2015. https://www.fda.gov/downloads/drugs/guidances/ ucm291128.pdf. Accessed 28 Sept 2021.

21. World Health Organization. Regulatory expectations and risk assessment for biotherapeutic products. 2014. http://www.who. int/biologicals/WHO_Risk_Assessment_for_Biotherapeutics 1st_PC_24_Jan_2014.pdf. Accessed 28 Sept 2021.

22. Castañeda-Hernandez G, Carbajai-Rodriguez L, Ceron-Rodriguez $\mathrm{M}$, et al. Are there biosimilar orphan drugs for Gaucher disease? GaBi J. 2019;8:71-5. https://doi.org/10.5639/gabij.2019.0802. 008.

23. Drelichman G, Castaneda-Hernandez G, Cem Ar M, Dragosky M, Garcia R, Lee H, et al. The road to biosimilars in rare diseases: ongoing lessons from Gaucher disease. Am J Hematol. 2020;95(3):233-7. https://doi.org/10.1002/ajh.25701.

24. GaBI Online. Generics and biosimilars initiative: biosimilar substitution in Europe. Belgium: Pro Pharma Communications International. http://www.gabionline.net/Reports/Biosimilar-substituti on-in-Europe. Accessed 26 June 2018.

25. Cerezyme (imiglucerase) [summary of product characteristics]. Cambridge: Sanofi Genzyme; 2020.

26. Cerezyme (imiglucerase). [package insert]. Cambridge; Sanofi Genzyme; 2020.

27. Starzyk K, Richards S, Yee J, Smith SE, Kingma W. The longterm international safety experience of imiglucerase therapy for Gaucher disease. Mol Genet Metab. 2007;90(2):157-63. https:// doi.org/10.1016/j.ymgme.2006.09.003.

28. Ponce E, Moskovitz J, Grabowski G. Enzyme therapy in Gaucher disease type 1: effect of neutralizing antibodies to acid beta-glucosidase. Blood. 1997;90(1):43-8. 
29. Rosenberg M, Kingma W, Fitzpatrick MA, Richards SM. Immunosurveillance of alglucerase enzyme therapy for Gaucher patients: induction of humoral tolerance in seroconverted patients after repeat administration. Blood. 1999;93(6):2081-8.

30. Drelichman G, Castañeda-Hernández G, Cem Ar M, Dragosky M, Garcia R, Lee H, et al. The road to biosimilars in rare diseases: ongoing lessons from Gaucher disease. Am J Hematol. 2020;95(3):233-7. https://doi.org/10.1002/ajh.25701.

31. European Medicines Agency. Guideline on good pharmacovigilance practices (GVP). Module VI: management and reporting of adverse reactions to medicinal products. EMA/873138/2011 Rev. London: European Medicines Agency; 2011.
32. European Medicines Agency. Guideline on good pharmacovigilance practices (GVP). Module I: pharmacovigilance systems and their quality systems. EMA/541760/2011. London: European Medicines Agency; 2011.

33. International conference on harmonisation of technical requirements for registration of pharmaceuticals for human use. ICH E2A: clinical safety data management: definitions and standards for expedited reporting; 1994.

34. International conference on harmonisation of technical requirements for registration of pharmaceuticals for human use. ICH E2C (R2): periodic benefit-risk evaluation report (PBRER). 2003. 